\title{
Correction: Predictors and Consequences of Veterans Affairs Mental Health Provider Burnout: Protocol for a Mixed Methods Study
}

Kara Zivin $^{1,2^{*}}$, MD, MS, PhD; Jennifer Kononowech ${ }^{1 *}, \mathrm{MSW}$; Matthew Boden ${ }^{3 *}, \mathrm{PhD}$; Kristen Abraham ${ }^{1,4^{*}}, \mathrm{PhD}$; Molly Harrod $^{1 *}$, PhD; Rebecca K Sripada ${ }^{1,2^{*}}, \mathrm{PhD}$; Helen C Kales ${ }^{5 *}$, PhD; Hector A Garcia ${ }^{6,7^{*}}$, PsyD; Paul Pfeiffer ${ }^{1,2^{*}}$, MD

${ }^{1}$ Center for Clinical Management Research, Department of Veterans Affairs, Ann Arbor, MI, United States

${ }^{2}$ Department of Psychiatry, University of Michigan Medical School, Ann Arbor, MI, United States

${ }^{3}$ Program Evaluation and Resource Center and VA Office of Mental Health Operations, VA Palo Alto Health Care System, Palo Alto, CA, United States

${ }^{4}$ Department of Psychology, University of Detroit Mercy, Detroit, MI, United States

${ }^{5}$ Department of Psychiatry and Behavioral Sciences, UC Davis Health, Sacramento, CA, United States

${ }^{6}$ VA Texas Valley Coastal Bend Health Care System, Harlingen, TX, United States

${ }^{7}$ Department of Psychiatry, University of Texas Health Science Center, San Antonio, TX, United States

*all authors contributed equally

Corresponding Author:

Kara Zivin, MD, MS, PhD

Center for Clinical Management Research

Department of Veterans Affairs

2800 Plymouth Road

Building 16

Ann Arbor, MI, 48109

United States

Phone: 17348453429

Email: kzivin@med.umich.edu

\section{Related Article:}

Correction of: https://www.researchprotocols.org/2020/12/e18345/

(JMIR Res Protoc 2021;10(1):e26934) doi: 10.2196/26934

In "Predictors and Consequences of Veterans Affairs Mental Health Provider Burnout: Protocol for a Mixed Methods Study" (JMIR Res Protoc 2020;9(12):e18345) the authors noted one error.

The Multimedia Appendix file attached to the originally published article has been removed, as the file contained some private financial information.
The correction will appear in the online version of the paper on the JMIR Publications website on January 12, 2021, together with the publication of this correction notice. Because this was made after submission to PubMed, PubMed Central, and other full-text repositories, the corrected article has also been resubmitted to those repositories.

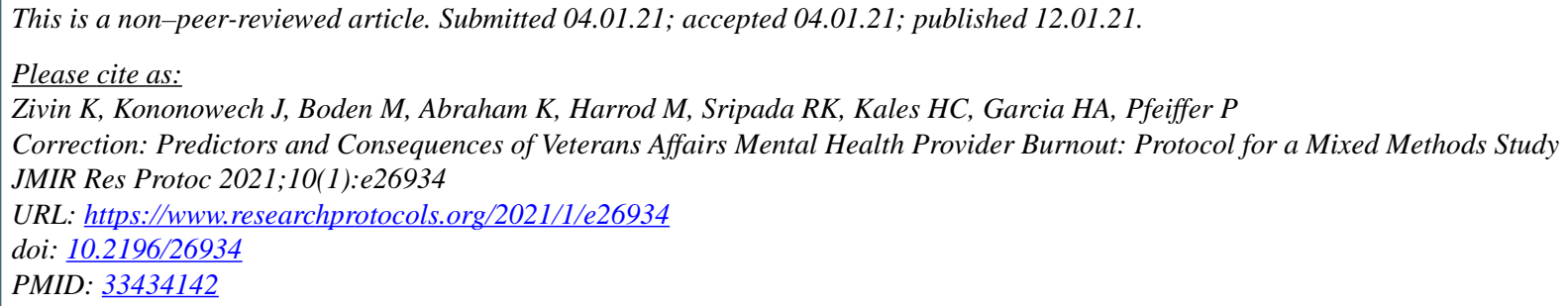


CKara Zivin, Jennifer Kononowech, Matthew Boden, Kristen Abraham, Molly Harrod, Rebecca K Sripada, Helen C Kales, Hector A Garcia, Paul Pfeiffer. Originally published in JMIR Research Protocols (http://www.researchprotocols.org), 12.01.2021. This is an open-access article distributed under the terms of the Creative Commons Attribution License (https://creativecommons.org/licenses/by/4.0/), which permits unrestricted use, distribution, and reproduction in any medium, provided the original work, first published in JMIR Research Protocols, is properly cited. The complete bibliographic information, a link to the original publication on http://www.researchprotocols.org, as well as this copyright and license information must be included. 